\title{
Geospatial Analysis of Indus River Meandering and Flow Pattern from Chachran to Guddu Barrage, Pakistan
}

\author{
Danish Raza* and Aqeel Ahmed Kidwai \\ Department of Meteorology-COMSATS University Islamabad, Islamabad, Pakistan
}

ABSTRACT

Natural and anthropogenic influence affects directly ecologic equilibrium and hydro morphologic symmetry of riverine surroundings. The current research intends to study the hydro morphologic features (meanders, shape, and size) of Indus River, Pakistan by using remote sensing (RS) and geographical information science (GIS) techniques to calculate the temporal changes. Landsat satellite imagery was used for qualitative and analytical study. Satellite imagery was acquired from Landsat Thematic Mapper (TM), Enhanced Thematic Mapper Plus (ETM+) and Operational Land Imager (OLI). Temporal satellite imagery of study area was used to identify the variations of river morphology for the years 1988,1995,2002,2009 and 2017. Research was based upon the spatial and temporal change of river pattern with respect to meandering and flow pattern observations for 30 years' temporal data with almost 7 years' interval. Image preprocessing was applied on the imagery of the study area for the better visualization and identification of variations among the objects. Object-based image analysis technique was performed for better results of a feature on the earth surface. Model builder (Arc GIS) was used for calculation of temporal variation of the river. In observation many natural factor involves for pattern changes such as; floods and rain fall. The object-oriented classification was applied for land use/land cover (LULC) features of the study area for the years 1988 and 2017 and abrupt change observed. Overall, 1988 to 2017 the Indus River in the study area has changed its path and pattern.

$\begin{array}{lll}\text { Keywords } & \text { *Address of Correspondence } & \text { Article info. } \\ \begin{array}{l}\text { Indus River, Remote Sensing, GIS, object- } \\ \text { based image analysis, LULC. }\end{array} & \text { danish_raza52@yahoo.com } & \text { Received: August 15, 2018 } \\ \text { Accepted: October 19, 2018 }\end{array}$

Cite this article: Raza D, Kidwai AA. Geospatial Analysis of Indus River Meandering and Flow Pattern from Chachran to Guddu Barrage, Pakistan. RADS J. Biol. Res. Appl. Sci. 2018; 9(2): 67-

Funding Source: Nil 74.

Conflict of Interest: Nil

This is an Open Access article distributed under the terms of the Creative Commons Attribution License (http://creativecommons.org/licenses/by/4.0), which permits unrestricted use, distribution, and reproduction in any medium, provided the original work is properly cited.

\section{INTRODUCTION}

Water is the renewable natural resource because it can be replenished after used. The Rivers flow the water from one place to another. The River channel normally contains a single stream of water but some river flow as multiple streams that are interconnected ${ }^{1}$. River water flows from upstream to downstream area with respect to elevation or topographical change. Indus River (IR) lies in northwestern (NW) part of southern Asia within the boundaries of China, Pakistan, India and Afghanistan ${ }^{2}$. Northern area of Pakistan contains Pamir mountain ranges and the Karakoram which make enough substantial topography of Indus River ${ }^{3}$. Indus River is a main tributary of Pakistan its starts from the northern area of Pakistan and end in Arabian Sea ${ }^{4,5}$. At the downstream of Panjnad upper side of Mithankot five major rivers from east (Jehlum, Chenab, Ravi, Beas and Sutlej) meets with Indus River. These five rivers fall into the Arabian Sea with the flux of sediments ${ }^{5}$. These Rivers are flowing through the Punjab Province densely populate and agricultural areas. At the downstream of Mithankot, Indus 
River has no dam and water flow with high magnitude without any interruption. River pattern changes take place at above the delta, especially near Kashmore and Sehwan and old paths can be recognized towards the Indus Delta in lower Sindh ${ }^{6}$. Due to the climate change heavy floods occurred in Indus River. The rise in temperature is the major cause of snow melting as well as change in rainfall cycle on the watershed area of Indus River cause of floods. In Indus River thirteen super floods and high floods occurred in the years 1955, 1956, 1957, 1958, 1959, 1964, 1973, 1975, 1976, 1978, 1983 , 1986, 1988, 1989, 1992, 1995, 1997 and $2010^{7}$. Remote sensing and GIS (Geographic Information System) approach is very useful in river morphological changes detection. GIS and remote sensing are used to calculate scattering of unusual and difficult areas to monitor in a cost-effective way with a high accuracy level ${ }^{8}$. Rivers are the natural feature on the earth surfaces that change the shape and size either by increasing or decreasing flow with the passage of time due to erosion, sedimentation and deposition. The gis-based analysis allows the river management and decision-making process ${ }^{9}$. Monitoring of the temporal morphological changes is not easy with the traditional methods. Remote sensing and GIS provides a possible solution to evaluate these changes in less time with quality work. Accurate, fast and costeffective information can be achieved easily ${ }^{10}$. Remote sensing and GIS are essential to identify these changes in a cost-effective way. Satellite imagery of the land surface with the passive sensors allows the detection and perception of ground objects ${ }^{11}$. GIS technique used for the observation of spatial and temporal trend of river and its association with other features ${ }^{12}$. In object-oriented classification, exported data in vector format in form of polygons that contain all the attribute information ${ }^{13}$. Land use planning do not possible without the satellite imagery. GIS and Remote sensing method used for change detection of land ${ }^{14}$. Remote Sensing is a tool to help in detecting the degree of land use land cover change that has taken place on river watershed ${ }^{15}$. On the other hand, statistical analysis performed by using Arc GIS: Model builder that is a graphical user interface that represented by diagrams to create, edit and execute the geospatial work ${ }^{16}$. The purpose of this research is to observe the
Indus River (Chahcran-Guddu) temporal flow pattern and meandering changes because the variations in river flow pattern occur due to flow of water with passage of time. Temporal pattern of river flow identification is the main purpose of the study. Land cover changes will be identified after the object-oriented classification of an area of interest to establish the scenario of land cover changes.

\section{MATERIAL AND METHOD}

\section{Study Area}

Geographically study area is located at $28.31^{\circ}-28.99^{\circ} \mathrm{N}$, $69.54^{\circ}-70.49^{\circ} \mathrm{E}$ (see Fig. 1). The length of the study area is around $88 \mathrm{~km}$ from Chachran to Guddu Barrage. This study area was chosen because of the water flow is very high due to all river of Punjab meet at the point that near to study area. Table 1 is showing the major settlements around the study area. Guddu Barrage was constructed to distribute the flow of water. Indus River is the biggest river in Pakistan that fall into the Arabian Sea 4,17 . The study area was chosen for flow pattern observation by using Landsat satellite images. Guddu Barrage is located near Kashmore alongside of Indus River. The construction of Guddu Barrage was completed in 1962. The maximum discharge capacity of Guddu Barrage is 1200000 cusecs $\left(\mathrm{m}^{3} / \mathrm{s}^{-1}\right){ }^{18}$. Main purpose of Guddu Barrage is to distribute the water flow for irrigation ${ }^{19}$.

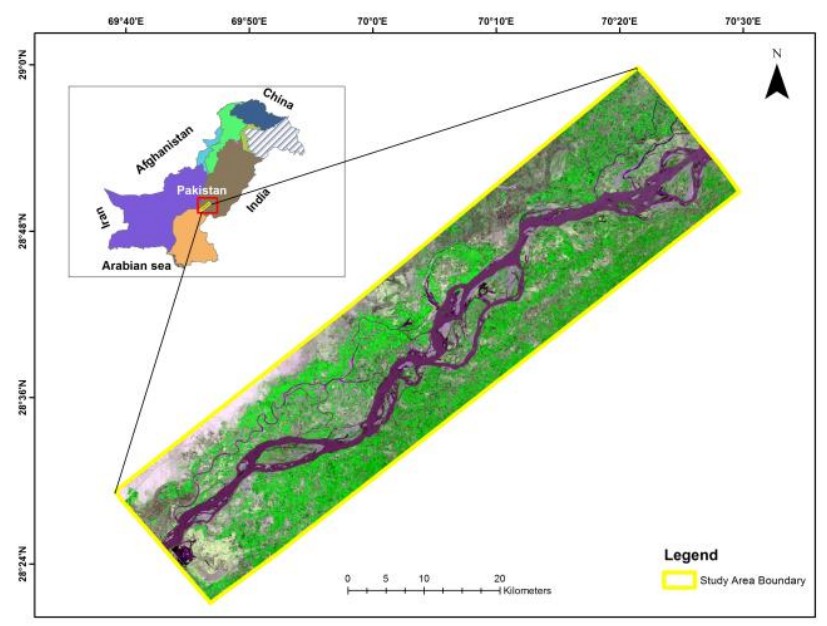

Fig. 1: Location map of the study area, Indus River (Chachran to Guddu Barrage). 
Table 1: Major settlement around study area (Indus River).

\begin{tabular}{cc}
\hline Northern West & Southern East \\
\hline Mithankot & Chachran Sharif \\
\hline Rojhan & Dilkusha \\
\hline Shahwali & \\
\hline
\end{tabular}

\section{Data and Analysis}

Multispectral Satellite images of 151 paths and 40 rows were downloaded from the free available website of United States Geological Survey (USGS). Satellite images from 1988 till 2017 with the gap of almost 7 years were downloaded. Landsat-5 TM (Thematic Mapper) images were acquired for the years of 1988, 1995, 2009 and Landsat-7 ETM+ (Enhanced Thematic Mapper Plus) for the year 2002 was downloaded. Meanwhile, Landsat-8 OLI (Operational Land Imager) data was used for the year 2017 (see Table 2). The Landsat data used in the process were already geo-referenced with the world geodetic system (WGS-84) and Universal Transverse Mercator (UTM), zone 42, north projection. The satellite images were obtained of only for the summer season to avoid seasonal water variations. Because in monsoon season river is under flooding consequently variations and changes of the river may not be easy observed. In the summer season, there is a controlled water flow in the river and flow pattern changes are easily identified using satellite images. Image preprocessing performed on the acquired satellite imagery. Atmospheric corrections and subset of satellite imagery of the area of interest were done by using the shape file of the study area.

Table 2: Landsat sensors specification.

\begin{tabular}{cccc}
\hline Satellite & Sensor & Resolution & Date \\
\hline & & & $06 / 12 / 1988$ \\
Landsat 5 & TM & \multirow{2}{*}{30 meters } & $15 / 05 / 1995$ \\
& & & $22 / 06 / 2009$ \\
\hline Landsat 7 & ETM+ & $26 / 05 / 2002$ \\
\hline Landsat 8 & OLI & $27 / 05 / 2017$ \\
\hline
\end{tabular}

\section{Object Based Image Analysis}

Object-oriented classification technique has a higher accuracy level to classify the satellite imagery as opposed to old traditional classification techniques ${ }^{20}$. The objectoriented classification was performed on pixel's values of Landsat data of 1988, 1995, 2002, 2009 and 2017 only on the study area. Overall observation based upon the temporal changes reliable due to the accuracy of results to enhance calculations results which are also the main objective of the research. The resultant image detected the river water, vegetation, barren and built up areas.

\section{Segmentation Based Classification}

Segmentation of the objects depends upon shape parameters that indicate how objects are created. It will depend upon the size of the segments, the larger the segments smoothing is also required, compactness value and shape size have an important role to create appropriate segments. Compactness is basically the procedure of merging features segment. The image displays clear segmentations with the targets (features). This may be realized that water has differences in reflectance because it could be clear, muddy and or intrusions. The segments are generated when the objectoriented process has been run, and they based on the target clustering (pixels). The image is divided into many objects and it is based upon the standard of nearest neighbor. Every image of Landsat has a number of pixels of different intensity but in object-based classification, objects are generated on the base of pixel values of same target or the pixels that have the almost similar intensity and increase the feature deficiency. Two algorithms used in the object-oriented method; one is a multi-resolution segmentation and the second is knowledge-based classification. In the first step of segmentation, the desired segmentation of that object is made.

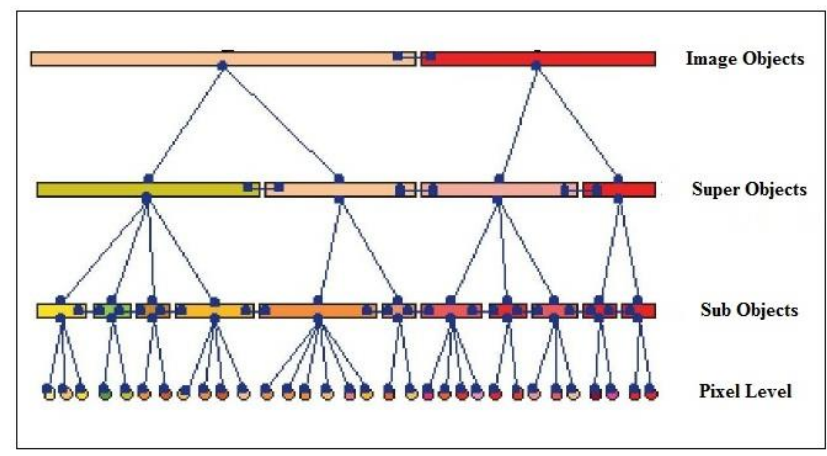

Fig. 2: Hierarchy of raster dataset in object-oriented classification (source: Benz et al. ${ }^{21}$ ). 
Later using the merging technique, the neighboring similar objects are merged to form bigger object (Fig. 2). Then, these bigger objects are merged on the basis of color (intensity), shapes and digital numbers of the objects. Knowledge-based (shape, size, texture and DN values) classification on the generated segments. Yu describes that object-based classification is based upon the object segments. He describes that the classes of features and segments for the classification of remotely sensed data generated according to the objects ${ }^{22}$. The scale parameter directly depends upon the segments, when the number of segments increase than the scale parameter is small because objects creation depends upon the value of scale parameter ${ }^{23}$. In this research, the multi-resolution segmentation algorithm is used to generate the segments according to the dataset. To generate accurate segments, the value of the scale parameter is set at five on the basis of the targets (features) in imagery. According to requirement, the scale parameter is necessary to achieve the goal that is used to increase or decrease the segments. For the composition of homogeneous criterion, the values that are used for shape and compactness is 0.1 and 0.3 respectively. Algorithms that are applied on the data are nearest neighbor; geometry and layer value standard applied. For the purpose of classification; algorithm is named as classification which is used to execute the classification results. To obtain reliable results 0.3 factor value is applied to avoid any mixed pixel effect. Segmentation of the objects is depending upon shape parameters that indicate how objects are created. It will depend upon the size of the segments, the larger the segments smoothing is also required, if the segments are smaller in size, it is necessary to apply the smoothness. In this research compactness and shape size value have been used 0.3 and 0.1 respectively. The smoothing was required for balance the homogenously of segments shape. The classes were labeled as water, vegetation, built-up, barren land after the segmentation process. Sampling of the objects was carried to separate the classes. The nearest neighbor algorithm was applied based on the layer (band) value and the geometry of the object. After the sample selection; algorithm of classification is used to execute classification results when all the sampling has been done. Later, the result could be exported into shapefile to use in GIS software.

\section{Modal Builder (Arc GIS)}

A detailed analysis has been carried out for the change of course of the river i.e. meandering, change of flow pattern etc. For the observation of change in pattern for the years 1988 and 2017 in the study area has noticeable. The study was carried out to observe the temporal changes according to its meandering and flow pattern. The study region has tremendous changes due to flow in form of its path to the area of the river in this research divided into several zones with respect to its meandering changes in multiple directions as observed in the results selection. Division of study region in multiple zones is useful to observed multi-variations in the large study area ${ }^{24}$. These changes were studied and analyzed using the overlay operations such as intersect, erase, and union to calculate the changed area. The influence of various factors over the river sinuosity was studied using the overlay analysis in the GIS. Three overlay operations, intersect, erase and the union was applied simultaneously.

\section{RESULTS \& DISCUSSIONS}

In this research, the flow pattern of Indus River (Chachran - Guddu) for the period of 30 years from 1988 to 2017 was observed. The object-oriented classification was applied on Landsat satellite for extraction of the results according to the shape of river body. The only reason for using object-oriented classification is that segments are generated according to the targets (features) specified. Object-oriented classification technique is applied to the imagery of Landsat 1988. The area of water body in 1988 was $195.9 \mathrm{~km}^{2}$. Fig. 3 shows the Indus River flow pattern from northeast to southwest and the area of the river in 1995 was $193.3 \mathrm{~km}^{2}$. From the above results in 1988, the area of water body was large as compared from the year of 1995. In 1995 the area of water body decreased with the difference of $2.6 \mathrm{~km}^{2}$. The area of water body in 2002 was $248.3 \mathrm{~km}^{2}$ and the area of the water body increased to $55 \mathrm{~km}^{2}$ according to the comparison of 1995 imagery. The flow pattern of water body from Chachran to Guddu Barrage in 2009 has variations and the area of water body in 2009 was $285.2 \mathrm{~km}^{2}$. The difference between the water bodies of 2002 and 2009 was $36.9 \mathrm{~km}^{2}$ that observed. Fig. 2 also shows the flow pattern of water body in 2017 that indicates the river in 2017 was $207.4 \mathrm{~km}^{2}$. 


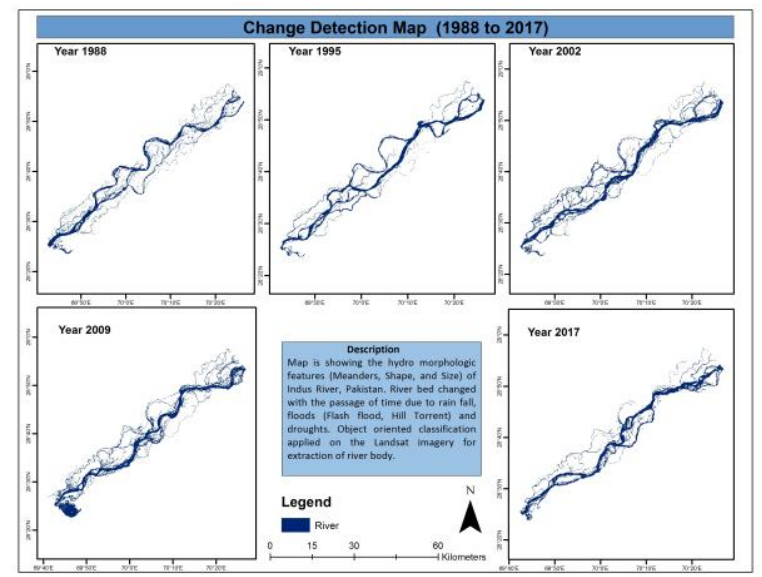

Fig. 3: Resultant map of object oriented classification for change detection.

Summarizing the results of all the maps that are generated from object oriented classification technique, Table 3 showing change in specified time frame.

Table 3: Results of temporal variations that occurred in observed period.

\begin{tabular}{ccc}
\hline Observed Period & $\begin{array}{c}\text { Overlapped Area } \\
(\%)\end{array}$ & $\begin{array}{c}\text { Spatially } \\
\text { Changed (\%) }\end{array}$ \\
\hline $1988-1995$ & 39.81 & 60.19 \\
\hline $1995-2002$ & 40.62 & 59.38 \\
\hline $2002-2009$ & 47.62 & 52.38 \\
\hline $2009-2017$ & 52.31 & 47.69 \\
\hline
\end{tabular}

Meandering and Flow Patten Observation for the Years 1988 and 2017

Area of the river increased up to $11.5 \mathrm{~km}^{2}$ in 2017 which makes the total area of water body $207.4 \mathrm{~km}^{2}$. The modal that builds (Fig. 4) to observe the change in river pattern indicates the abrupt variations such as; an area of $25.49 \%$ of the river in 2017 overlapped with the old position of the river 1988 However, abrupt changes could be observed in Fig. 5 where it can be seen clearly that $74.51 \%$ area of the river in 2017 has changed its flow pattern due to the temporal variations as compared to 1988. Overall scenarios in results show the temporal variation in river flow pattern and meandering within 30 years' gap. An observed variation indicates that there are many factors involved in the changed in the condition of water level and path change processes such as rainfall and floods. According to Memon flash flood is the main reason that involves in erosion on the river bed, because of the (catchment area of province Baluchistan) flow of water towards Indus River, eventually spatial and temporal changes occur caused by the floods. Mainly, Jacobabad, Kashmore and Shahdadkot areas get affected in floods and eventually the agricultural land, roads, forest, and other damages occur ${ }^{25}$. Also, he indicates the factors that may involve in the water flow in this region so, the results of the research show the abrupt change in the resultant map (Fig. 5). Consistency flow of the river in its channel is the source of energy which removes every object that falls in its way as the resulting shape of the river changed ${ }^{26}$.

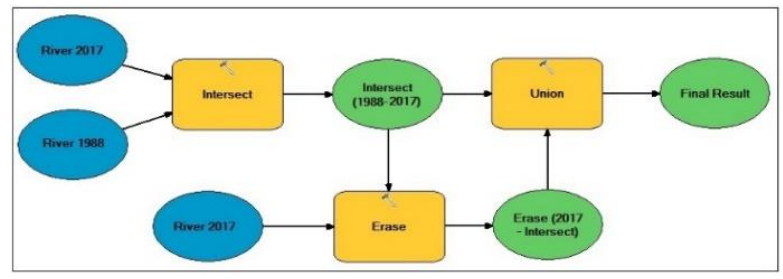

Fig. 4: Model builder process for identification of river pattern changes in between the years 1988 and 2017.

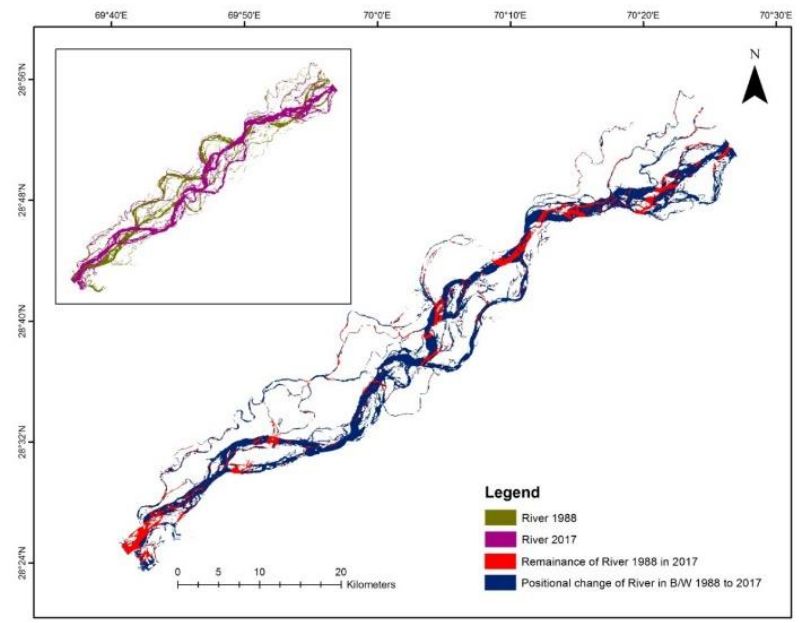

Fig. 5: River flow pattern in 2017, Model builder result shows the red color that indicate the remain of river 1988 and blue color indicate river path that changed till 2017.

Salma divided the study area into five zones according to the means and median of climate to observe the climate change ${ }^{24}$. In this research, the study area is divided into 5 zones based on a meandering, flow pattern and direction of temporal variations in the path of the river. In this research, the study area is divided into 5 zones based on a meandering, flow pattern and direction of temporal 
change path of the river. Zone 1 in Fig. 6 shows the temporal trend of the river in zone 1 where the river shifted up to $2.7 \mathrm{~km}$, the trend of river pattern/meandering changed towards the South East direction. It is clearly observed in zone 2 that the river changes the trend of flow in NW direction and changed the path to almost $2.8 \mathrm{~km}$ away from the original path. Moreover, in zone 3 and zone 4 respectively river flow pattern changed in SE and in NW that also has an abrupt change in form of meandering of the river. The river changed the path up to $7.7 \mathrm{~km}$ that is a large deviation from the original path. In zone 5 it is observed that the river shifted its path slightly in NW direction again. River pattern and path of the river changed up to $2.5 \mathrm{~km}$ in this region.

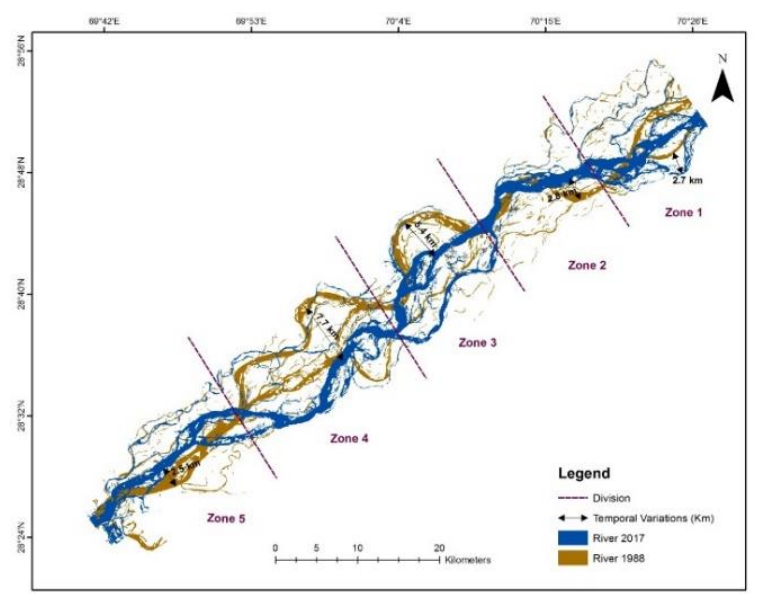

Fig. 6: Positional variation in flow of Indus River (Chachran-Guddu) from 1988 to 2017.

The floods are caused by the fluvial hazards in the current study area. He also describes that the unpredictable floods were observed at Guddu Barrage from 1973 to 1995 and also in 2010. It also faced ten super floods from 1973 to 2010 (an average of five years' gap) and seven very high floods (an average of seven years gap) from 1981 to 2015. Superfloods peak discharge varies from 26,740 to $33,951\left(\mathrm{~m}^{3} / \mathrm{s}\right)$ while a very high flood discharge varied from 20,077 to $23,524\left(\mathrm{~m}^{3} / \mathrm{s}\right)$. Eventually, these variations in flooding cause severe meandering and changes in the flow pattern, trend, and directions. The floods at Guddu Barrage receive heavy rainfall in the northern areas of Pakistan is the major cause of rising water level in Indus River ${ }^{7}$. Graph (Fig. 7) shows the temporal trend of rainfall that derived from annual average rainfall $(\mathrm{mm})$ of Punjab Province observatories for the years 1988 to 2017 . Rainfall data acquired from the Pakistan Meteorological Department (PMD). Rainfall data based on the measurement of Bahawalpur, Bahawalnagar, Islamabad, Faisalabad, Rawalpindi, Jehlum, Khanpur, Lahore, Mianwali, Multan, Murree, Sargodha, Shorkot and Sialkot stations. Change in rainfall has effects on channel movement and these variations are the main cause of river positional change.

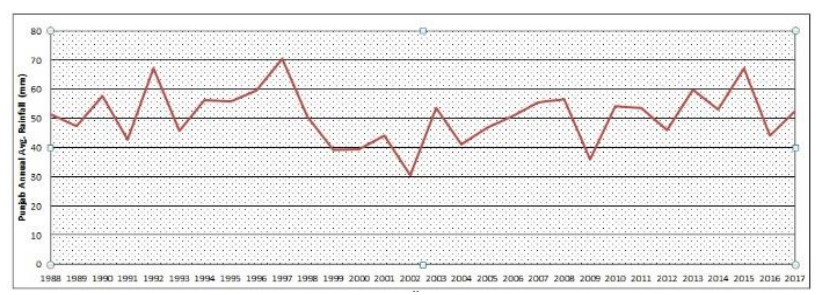

Fig. 7: Graph showing Punjab annual average rainfall $(\mathrm{mm})$ for observation of rainfall changes from 1988 to 2017 (PMD 27).

\section{Satellite Based Land Use I Land Cover Change Detection}

Due to the temporal variations in the flow pattern of the river; land use and land cover changes occur. Fig. 8 displays the map of land use/land cover classification for the years 1988 and 2017. Temporal changes can be observed in the land cover where the vegetation has decreased while the built up, barren land and water body have increased with the passage of time.

Table 4: Descriptions of land use/ land cover classes.

\begin{tabular}{ccc}
\hline Serial Number & Classes Name & Class color \\
\hline 1 & Built up & Dark Brown \\
\hline 2 & Barren Land & Olive \\
\hline 3 & Vegetation & Green \\
\hline 4 & Water & Blue \\
\hline
\end{tabular}

GIS is an important technology for temporal analysis otherwise change detection is very difficult. Change detection is possible with this technology in less time and cost ${ }^{10,28}$. In this research four LULC classes were used to observe the change (see Table 4). Fig. 9 shows the bar graph of the year 1988 and 2017 where it can be visualized increasing and decreasing trend of targets which are classified from Landsat satellite imagery by 
using the object-oriented classification. In 1988 vegetation can be seen in classified results, vegetation exists along the river. Abrupt changes occurred in 2017 where the vegetation became as barren land and converted into built-up areas. Temporal changes occurred in the downstream area (study area) after Panjnad Barrage due to the high flow of water 5 . The research also established a loss of vegetation has occurred where the river changed its flow path and pattern.

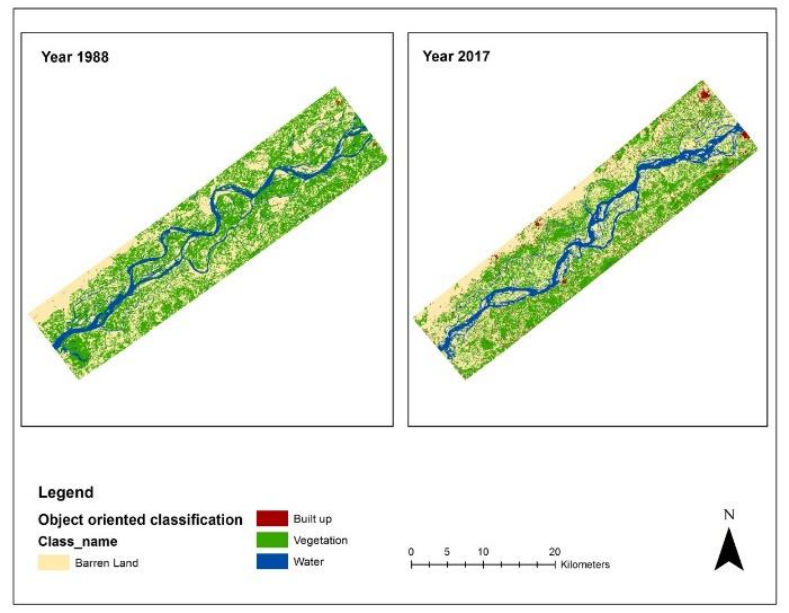

Fig. 8: Object oriented classified results of land use/ land cover change for the years 1988 and 2017.

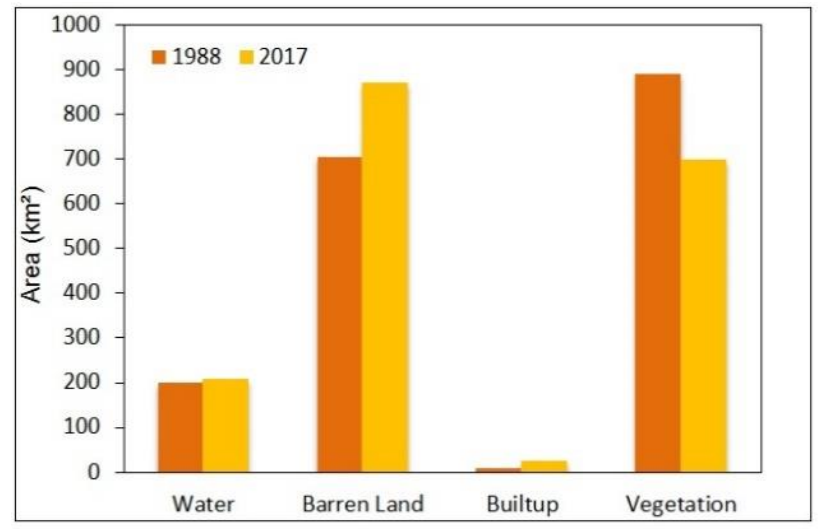

Fig. 9: Graph of temporal changes in land use/ land cover change in $\mathrm{km}^{2}$ for the years 1988 and 2017.

The research work also establishes that the ratio of barren land, built up and vegetation in 1988 was $39.08 \%$, $0.49 \%$, and $49.14 \%$ respectively. Barren land, built up and vegetation covered area as; $48.31 \%, 1.35 \%$ and $38.74 \%$ in 2017 the research shows that the built up and barren land increased but the vegetation deceased in the observed time period. Built up and barren land have been also increased $0.86 \%$ and $9.23 \%$ respectively. Vegetation cover in 2017 has decreased up to $10.4 \%$ with respect to the vegetation in 1988. The water of the river and built up area increased during the 30 years' gap.

\section{CONCLUSIONS}

In this research, Indus River (Chachran to Guddu Barrage) flow pattern and land use / land cover changes are analyzed. The results show that the water body has increased based upon the object-oriented classification. Water flow pattern changes (shape, size and path) occur over the years according to its flow as analyzed using the Landsat imagery of 1988 to 2017. Indus River (Chachran to Guddu Barrage) has variations in flow pattern with respect to the time. Large variations are observed in flow pattern and meandering since last 30 years in the between zones 3 and 4 of the study area yet starting and ending points of path of river encountered less changes with respect to middle of the study area. Object-oriented classification technique is best fit to detect the river morphology and results are satisfactory because image classified on the bases of their targets (objects) segment. The results show variations have occurred about 2.7 to $7.7 \mathrm{~km}$ in the river flow pattern. Study area fall at the border of Punjab Province and receives a huge flux of water flows towards the Guddu Barrage and eventually, variation occurs due to erosion or deposition. The research established that the vegetation has decreased and the water, built up and barren land have increased in observed time period.

\section{REFERENCES}

1. Walther JV. Earth's Natural Resources. Jones \& Bartlett Publishers; 2013.

2. Kravtsova VI, Mikhailov VN, Efremova NA. Variations of the hydrological regime, morphological structure, and landscapes of the Indus River delta (Pakistan) under the effect of large-scale water management measures. Water resources.2009; 36(4): 365-79.

3. Hewitt K, Wake CP, Young GJ, David C. Hydrological investigations at Biafo Glacier, Karakoram Range, Himalaya; an important source of water for the Indus River. Ann Glaciol.1989; 13: 103-8.

4. Hill D. The politics of water in South Asia. Transforming Cultures eJournal. 2006; 1(2): 135-158. 
5. Akhtar S. The south Asiatic monsoon and flood hazards in the Indus river basin, Pakistan. J Basic Applied Sci. 2011; 7(2): 101-15.

6. Hancock GS, Anderson RS, Whipple KX. Beyond power: bedrock river incision process and form. Rivers over rock: Fluvial processes in bedrock channels. 1998; 35-60.

7. MAHESSAR A, QURESHI A, DARS G, SOLANGI M. Climate Change Impacts on Vulnerable Guddu and Sukkur Barrages in Indus River, Sindh. SURJ)2017; 49(1):137-42.

8. Alam MS, Khan JA, Kushwaha SP, Agrawal R, Pathak BJ, Kumar S. Assessment of suitable habitat of near threatened Striped Hyena (Hyaena hyaena Linnaeus, 1758) using remote sensing and geographic information system. Asian J Geoinform. 2014; 14(2): 1-10.

9. Alam JB, Uddin M, Ahmed U J, Cacovean H, Rahman HM, Banik BK, et al. Study of morphological change of river old Brahmaputra and its social impacts by remote sensing. Geographia Technica. 2007; 2, 1-11.

10. Seker DZ, Goksel C, Kabdasli S, Musaoglu N, Kaya $S$. Investigation of coastal morphological changes due to river basin characteristics by means of remote sensing and GIS techniques. Water Sci Technol. 2003; 48(10): 135-42.

11. ljaz MW, Siyal AA, Mahar RB, Ahmed W, Anjum MN. Detection of Hydromorphologic Characteristics of Indus River Estuary, Pakistan, Using Satellite and Field Data. Arab J Sci Engineer. 2017; 42(6): 253958.

12. Porter MD, Massong TM. Analyzing changes in river channel morphology using GIS for Rio Grande silvery minnow habitat assessment. GIS/Spatial Analyses in Fishery and Aquatic Sciences.2004; 505: 433-446.

13. Zhou W, Troy A. An object oriented approach for analysing and characterizing urban landscape at the parcel level. International J Rem Sens. 2008; 29(11): 3119-3135.

14. Bato VA, Paningbatan Jr EP, Bartolome BJ. High resolution satellite data for comprehensive land-use planning. J Environ Sci Manag. 2011; 14(1):12-23.

15. Hua AK. Land Use Land Cover Changes in Detection of Water Quality: A Study Based on Remote Sensing and Multivariate Statistics. J Environ Pub Health. 2017; 2017:1-12.

16. ESRI. Model Builder for ArcView Spatial Analyst 2. Redlands, CA: ESRI Press; 2000.
17. Khan B, Iqbal MJ, Yosufzai MA. Flood risk assessment of river Indus of Pakistan. Arab J Geosci. 2011; 4(1-2): 115-22.

18. Inam A, Clift PD, Giosan L, Tabrez AR, Tahir M, Rabbani MM, et al. The geographic, geological and oceanographic setting of the Indus River. Large rivers: geomorphology and management. 2007; 333345.

19. Chaudhry SA. Pakistan: Indus Basin Water StrategyPast, Present and Future. Lahore J Econom. 2010; 15: 187-211.

20. Akar Ö, Güngör $O$. Classification of multispectral images using Random Forest algorithm. J Geodesy Geoinform. 2013; 1(2).

21. Benz UC, Hofmann P, Willhauck G, Lingenfelder I, Heynen M. Multi-resolution, object-oriented fuzzy analysis of remote sensing data for GIS-ready information. ISPRS J Photogramm Rem Sens. 2004; 58(3-4), 239-58.

22. Yu Q, Gong P, Clinton N, Biging G, Kelly M, Schirokauer D. Object-based detailed vegetation classification with airborne high spatial resolution remote sensing imagery. Photogramm Engineer Rem Sens. 2006; 72(7): 799-811.

23. Matinfar HR, Sarmadian F, Alavi Panah SK, Heck RJ. Comparisons of object-oriented and pixel-based classification of land use/land cover types based on Lansadsat7, Etm+ spectral bands (case study: arid region of Iran). American-Eura J Agri Environ Sci. 2007; 448-56.

24. Salma S, Shah MA, Rehman S. Rainfall trends in different climate zones of Pakistan. Pak J Meteorol. 2012; 9: 37-47.

25. Memon AA, Muhammad S, Rahman S, Haq M. Flood monitoring and damage assessment using water indices: A case study of Pakistan flood-2012. Egyp J Rem Sens Space Sci. 2015; 18(1):99-106.

26. Garde RJ. History of fluvial hydraulics. New Age International; 1965.

27. PMD. Pakistan Meteorological Department, PMD Headquarters Office, Sector $\mathrm{H}-8 / 2$ IslamabadPakistan; 2017.

28. Rawat JS, Kumar M. Monitoring land use/cover change using remote sensing and GIS techniques: A case study of Hawalbagh block, district Almora, Uttarakhand, India. Egyp J Rem Sens Space Sci. 2015; 18(1): 77-84. 